\title{
The 'principles' paper: some thoughts on an unusual hybrid
}

\author{
Andrew K. Shenton
}

\begin{abstract}
For years, 'principles' papers have made an important contribution to LIS literature and their influence on subsequent writers has been considerable. They make a series of concise claims in relation to a topic, which are usually supported by a variety of evidence and are pertinent across time and space. These claims have emerged from the literature or are derived directly from the author's own experience. In writing such a piece, research students may seek to enhance their abstract thinking abilities, whilst practitioners benefit from considering their work more critically and from contextualising their day-to-day experience in terms of wider knowledge. Although 'principles' papers are difficult to construct, a wouldbe writer should not be deterred, as readers are likely to appreciate the ease with which the main claims can be seen, and the paper may form a significant step towards the creation of higher order work.
\end{abstract}

\section{Introduction}

Prompted by parallels between the royal wedding of 2011 and the ceremony uniting Lady Diana Spencer with the Prince of Wales thirty years earlier, many of us will no doubt have recently recalled in our more reflective moments some of the memorable events of 1981. Whilst musical and sporting highlights from that time included ABBA's final studio album, The Visitors, and England's Ashes victory in one of the most exciting Test series cricket has ever seen, the publication of an ambitious book by Donald Urquhart did not go unnoticed in the world of LIS. According to Maurice Line, himself a former Director General of the British Library Lending Division, Urquhart ranks as "one of the greatest innovators, practitioners, thinkers and personalities the library profession has ever had" (Line, 1994). Urquhart's monograph defines eighteen "principles of librarianship" formulated to guide the actions of information specialists, irrespective of social and technological change (Urqhuart, 1981).

\section{Author}

Dr. Andrew K. Shenton is Chief Research Officer at Monkseaton High School, in the north-east of England. He is also responsible for the institution's library.

E-mail: ashenton1@hotmail.com

Received 17 March 2012

Accepted 27 June 2012 
Even as long ago as 1981, the concept of basing a treatise on a number of principles imbued with the personal beliefs of the writer was by no means new in LIS. Several years earlier, Dervin (1976) had written a paper revealing her attitudes to ten questionable assumptions which, she had suggested, hindered the understanding of people's information needs. Dervin's work has proved highly influential and, some three decades after her article was published, Case (2007) chose to conclude his study of information behaviour by reinterpreting her ten arguments, merging some and adding two of his own.

Although Urquhart (1990) would later admit his disappointment at the reaction that his principles had received, his book nonetheless made an impact on writers and academics. Nearly thirty years on from its first appearance, Shenton and Johnson (2010) took the rudiments of the conceptual structure as a model and presented five of their own statements, dealing with caveats, anomalies and dilemmas affecting the modern school librarian. In an earlier paper Shenton (2007) had confined himself to outlining paradoxes associated with young people's information behaviour. This paper has since been cited on several occasions and formed the basis of a whole new article (i.e. Shenton, 2010). Writing for Polish teacher-librarians, Staniów (2008) describes the featured paradoxes at some length. In addition, the Informed Librarian Online (2008) has publicised the paper and it has been listed as recommended reading for one of the courses offered by the Palmer School of Information and Library Science at Long Island University in the USA.

Undoubtedly the most famous principles in our field are those presented by Ranganathan (1931). Chowdhury et al. go so far as to assert that they have been "the key driving force for the profession" since their publication $(2008,234)$. It is a measure of their impact on thinking that Noruzi (2004) is able to cite a series of later writers who have stated their own principles and laws based on Ranganathan's work. According to Gorman (1998), Ranganathan believed that all human activities could be subjected to analysis by scientific method, and rigorous examination of LIS phenomena could lead to the formulation of empirical "laws". Whilst Gorman recognises that Ranganathan's five laws are of a type fundamentally different from those commonplace in sciences such as physics, he suggests that, since each is based "on observation and analysis by a trained mind", they cannot be dismissed as "mere generalities" $(1998,55)$. It is this middle ground positioning that renders their status that of 'principles'. In a work that discusses Ranganathan's laws, Gorman (1998) offers his own "meditations" as an information professional, each of which begins, "I will...". Like Urquhart's principles, these embody the beliefs of the author, although since they are more personal, aspirational statements, together forming a code of conduct that may be adopted by young librarians, they are clearly quite dissimilar in nature to the kind of 'principles' that will be discussed here.

The interest that articles devoted to 'principles' would seem to attract, at least in LIS, has been a significant factor in motivating this writer to examine here the characteristics of such papers. Drawing on various examples, he aims to raise the profile of this type of writing and demonstrate, to students, other academics and practitioners who may consider producing such a paper, its potential and challenges. 


\section{Intended readership}

It is important to appreciate from the outset that different kinds of 'principles' paper will be written by different kinds of writer, and the piece presented here is intended to support the efforts of each by offering a review of work of this type that is familiar to the author and which relates to his own area within LIS. It also provides direct guidance on how such a paper may be produced. After reading the article, prospective authors will be better acquainted with nature of a 'principles' paper, be more aware of its different varieties, and understand more fully the contribution to scholarship that such writing can make. PhD students may be encouraged to prepare a 'principles' paper in the knowledge that it will develop their ability to draw out from the literature fundamental statements that can be made in relation to their particular area of interest. Higher degree supervisors and research methods lecturers may ask their students to write a 'principles' paper because it can afford a means to help the learners to gain, and then to practise, higher level thinking skills. According to Salmon, " $\mathrm{PhD}$ work, as it is generally understood, demands the highest level of autonomous critical reflection" (1992, $3-4)$, and the setting of tasks involving the writing of such a paper can form one step towards achieving the necessary state of mind.

Whilst 'principles' papers can be written in the early phases of a research project, with the individual intent on distilling key findings from a body of literature, the scholar may also take on the task in the later stages, when it provides a vehicle for investigating the extent to which their own discoveries are consistent with wider patterns in established knowledge. Practitioners, for their part, may wish to exploit their own experience, coupled, perhaps, with anecdotal evidence from colleagues and some insights from the literature, especially those gleaned from professional periodicals, to formulate their principles. This action enables them to consider, from a more dispassionate angle, issues surrounding their own workplace activity and to explore how their observations relate to those of other professionals. The eventual outcome - the 'principles' themselves - can ultimately be used to guide and inform future practice.

It is instructive to explore how the writing of a 'principles' paper helps to facilitate the acquisition of skills which feature prominently in certain generic frameworks. In the renowned Bloom's Taxonomy, synthesis - one of the breakdown's most challenging skills - involves the combining of elements from an original entity in order to create a new one (Bloom, 1956). If this is interpreted in terms appropriate to the 'principles' paper, clearly the original entity may be understood to take the form of the source material under examination, and the new entity comprises the set of principles that is constructed. In discussing the ability to think flexibly - one of their sixteen advantageous "Habits of Mind" - Costa and Kallick (2009) write of the importance of taking a "macro-centric" perceptual position. Here, the authors explain, the individual adopts a "bird's eye view... useful for discerning themes and patterns from assortments of information". Again, it is not difficult to see how the writing of a 'principles' paper in which the author augments their own discoveries with those from the literature demands that such a perspective be taken. 


\section{Key characteristics}

Essentially, papers of the kind under scrutiny in this article present assertions, supported by appropriate evidence, that pertain to a certain area of knowledge. The statements made can be reduced to a relatively small number of concise, bulleted points. Urquhart $(1981,10)$ writes, "it is desirable to be able to set down the essence of a principle in one sentence. Otherwise there is the danger that the principle will be lost in a mass of words". Whilst the kernel of the principle can be expressed with brevity, it must be expanded sufficiently in the main text to ensure that the author's point is not subject to misinterpretation, and the evidence that has led to the claim must, of course, be presented in full. As Foskett $(1982,138)$ appreciates, it is dangerous to make sweeping statements on the basis of "limited experience", and depth of reporting is vital if the reader is to determine whether there is sufficient proof to justify each assertion. Whilst some authors lead with the principle and then discuss it through the coverage of appropriate material (e.g. Dervin, 1976; Dervin, 1997; Faibisoff and Ely, 1976), others prefer to consider the relevant evidence first and then conclude with an encapsulating statement (e.g. Shenton, 2007).

\section{Applicability}

Urquhart (1981) maintains that one of the key characteristics of a principle is that it should remain pertinent irrespective of different situations and the passage of time. This ground rule can provide inspiration for future researchers - they may wish to ascertain the suitability, in other contexts, of the principles formulated by an author. As Beaulieu (2003) points out, a model can be tested by further empirical investigation, and principles are similar in this sense, as they, too, can be revisited, and perhaps ultimately refined, through wider study. Some 'extension work' has been undertaken by Shenton in terms of his paradoxes of young people's information behaviour. Looking to add breadth to an analysis which, in the first instance, concentrated mainly on findings from research, he has introduced a practitioner's perspective by drawing on ideas from Gorman, who served as Dean of Library Services at California State University for nearly twenty years (Shenton, 2010).

One of the clearest differences between Urquhart's 'principles' and the caveats, anomalies and dilemmas of Shenton and Johnson (2010) is that, whilst the former are portrayed by their author as generally applicable, Shenton and Johnson have less lofty aspirations. They recognise that, on the most fundamental level, their statements may be regarded as 'truths' that pertain to their own school library. Seeing these assertions for themselves will help readers to understand the nature of principles in more concrete fashion. Thus they are listed below.

- [Library] issue figures for fiction may reflect the borrowers' wider circumstances, rather than their literary inclinations.

- Use of non-fiction books [in a library] may be substantially better than issue figures may suggest. 
- Widespread use of the World Wide Web has undermined the role of the school librarian in ostensibly unconnected areas.

- Rigorous stock deselection activity can have far-reaching implications for users' perceptions of the school library.

- Attempts to meet one of the school library's key missions frequently adversely affect the organisation's effectiveness in satisfying another.

Authors wishing to demonstrate the wide-ranging relevance of their assertions have two options available. Firstly, even if they have begun with observations that are rooted in one particular situation, they can use additional insights to make them more widely applicable. They may, for example, draw on material that enables them to track a certain theme over time and across different settings. In explaining the concept of "circling reality", Dervin writes of "the necessity of obtaining a variety of perspectives in order to get a better, more stable view of 'reality' based on a wide spectrum of observations from a wide base of points in time-space" $(1983,7)$. Such an expansive approach is perhaps the most obvious way in which the author can progress from a micro level to the more macro scale envisaged by Urquhart (1981). Alternatively, authors may take a less ambitious line on applicability. They may not feel it a priority to accumulate a weight of diverse evidence and concentrate instead on drawing, from individual scenarios, generic conclusions that will find resonance with readers, e.g.:

Although no claim is made that the specifics of the situations discussed here emerge universally, the broader matters raised with regard to the employment of valid and pertinent performance measures, the difficulty of promoting both the book collection and the information specialist in the face of technological innovation and the pressures of satisfying organisational aims that may contrast and even appear to conflict, may well strike a chord with readers working in a range of school libraries.

(Shenton and Johnson, 2010, 13)

\section{Origins of the ideas}

The genesis of the claims made will vary from one paper to another. Authors can formulate their principles entirely from the literature, or base them at least initially on their own experience, either in terms of research or practice. It may be, for example, that a $\mathrm{PhD}$ student who is finishing their project becomes aware that their essential findings can be summarised as certain "key statements", which they may then seek to explore outside the remit of their own study. Where the assertions made by an author are based on that individual's more personal perspectives or inclinations, these may be likened to hypotheses that are then subject to examination or elaboration. With respect to the more systematic, sources-inspired approach, Dervin (1997) points out in connection with her own work that the identification of themes is limited to those prevalent in the literature of which the author is aware. The same factor, of course, restricts the extent of the discussion that surrounds each individual issue, too. Comparisons can be made between the sources-inspired method and the way qualitative researchers work with data. Maykut and Morehouse explain how, in this sense, "what becomes 
important to analyze [sic] emerges from the data itself" $(1994,127)$, and understanding of the relevant phenomena is also gained from this content. When writing a 'principles' paper, it is the literature, rather than data, that forms the fodder. In each case, though, the material may be analysed dispassionately, with the individual having no underlying personal agenda to follow. A variation on the conventional line is taken by Williams and Rowlands, who use two types of published material to compile and then scrutinise a variety of statements commonly made in relation to the information behaviour of young people. They begin by investigating "opinion pieces" to identify such claims and then assess their validity against "the research literature" $(2007,12 / 29)$.

\section{From origin to use}

It is entirely possible for the creator of a set of principles to use ideas relating to one field of LIS for the benefit of another. This is especially true of work pertaining respectively to information behaviour and the design of information systems. Ellis explains that patterns detected in how users interact with information sources may be broken down into "basic behavioural characteristics", and the system that is created may be endowed with facilities that accommodate such characteristics, thereby enabling the user to recreate their behaviour when exploiting it $(1989,172)$. Thus principles which define the tendencies of users may form a significant input into the decisions made by designers when planning their systems. Similarly, in examining people's information needs it may be possible to arrive at a series of principles which define the characteristics of information that the research subjects consider prerequisites. These may then be recast in order to provide a specification that is of use to the designers of information systems and services. As Allen argues, the first element in a model for user-centred information system design lies in understanding the "goals, purposes, and objectives of the potential users of information systems being designed" $(1996,55)$. Conversely, it may be that a scholar intent on exploring human information behaviour infers their own principles relating to user needs after studying the priorities that have been established for an information system created to serve the population of interest. Ahituv and Neumann isolate several "categories of information system attributes" - specifically timeliness, content, format and cost $(1990,58)$. Some of these are subdivided, with "content" being broken down under the headings, accuracy, relevance, exhaustiveness, redundancy and level of detail. Where such criteria have emerged from research relating to user needs, subsequent user-focused principles based on inferences from the resulting criteria effectively return attention to the original starting point, thereby completing a full circle of investigation.

\section{Placement}

The 'principles' paper is seldom discussed at any real length by commentators describing the different types of manuscript that may be prepared by authors writing for publication. Indeed, it is not covered at all in Elsevier's guide to writing for academic and professional journals (Elsevier, 2007); nor does this form of work fit easily into any of the categories of paper defined by another major publisher, Emerald (2011). Whilst a particular example may share some 
commonalities with certain features of any of four of the Emerald types, there could well be marked discrepancies, too. In short, it has an identity that is unique to itself. Table 1 shows the similarities and differences that arise when the characteristics of a 'principles' paper are compared with those of four of the varieties of article outlined by Emerald.

\begin{tabular}{|l|l|l|}
\hline Paper types & Similarities & Differences \\
\hline $\begin{array}{l}\text { Conceptual } \\
\text { paper }\end{array}$ & May develop hypotheses & $\begin{array}{l}\text { May be more research-orientated } \\
\text { and focused on certain issues, } \\
\text { rather than discursive } \\
\text { Will not necessarily offer an } \\
\text { overview or historical } \\
\text { examination }\end{array}$ \\
$\begin{array}{l}\text { Literature } \\
\text { review }\end{array}$ & $\begin{array}{l}\text { Likely to concentrate on a } \\
\text { particular phenomenon } \\
\text { source material }\end{array}$ & $\begin{array}{l}\text { Does not specifically aim to } \\
\text { annotate or critique the literature } \\
\text { of a particular subject } \\
\text { May give special weight to } \\
\text { author's own research/experience } \\
\text { as a practitioner }\end{array}$ \\
Viewpoint & $\begin{array}{l}\text { May be based on the author's } \\
\text { opinion/interpretation }\end{array}$ & $\begin{array}{l}\text { May take a more objective and } \\
\text { detached approach when } \\
\text { exploring the pertinent literature }\end{array}$ \\
\hline
\end{tabular}

Table 1: Types of paper as defined by Emerald, compared and contrasted with the 'principles' paper.

\section{Challenges for the author}

The demands made on an author attempting to write a 'principles' paper are not to be underestimated. Indeed, they may seem particularly onerous when compared with those imposed on authors of papers of a different type. Writers intent on repackaging material from an existing product, as may be the case with students who have already prepared a dissertation or thesis, or professional researchers who have completed a report for the commissioning organisation, may find themselves virtually able to reproduce their work 'in miniature' or may concentrate on recasting, for a different readership, sections of the whole. In addition, any writer aiming merely to present an account of a project they have undertaken can revisit the conventions that have arisen in terms of how such writing should be structured. Shenton (2009) shows the resemblances that research in the social sciences bears to research in the natural sciences. As well as there being an essential similarity between the two sets of processes, there are marked similarities in how research in social and natural scientific inquiry are written up. By way of illustration, Table 2 juxtaposes the sections typically found in a social research paper with the equivalent headings that have for years been used by pupils in schools when setting down the details of scientific experiments. 


\begin{tabular}{|l|l|}
\hline Natural sciences experiment report & Social sciences research paper \\
\hline Aim & Problem statement; aims and objectives \\
Equipment; method & Methodology \\
Results & Findings \\
Conclusion & Conclusions and implications \\
\hline
\end{tabular}

Table 2: Comparison of the structure of a natural sciences experiment report with that of a social sciences research paper.

The structure employed when writing a social research paper, then, is not only well established; it is also consistent with norms associated with the reporting of other forms of scholarly activity. Some journals, in their notes to contributors, give their own guidance by prescribing a particular template for such accounts. The Journal of the American Society for Information Science and Technology (2011), for example, stipulates that the following headings be used:

- background and purpose of the project;

- methods, materials, procedures and equipment;

- findings, discussion and conclusions.

There are no comparable conventions with regard to the structuring of a 'principles' paper. Indeed, especially for an inexperienced writer, the freedom and more wide-ranging possibilities available may seem overwhelming.

Having determined the actual statements to be featured and the structure to be adopted, a major challenge for the author may lie in striking a balance in their piece between the use of their own material, in terms of either insights as a practitioner or illumination from their personal research, and that of others. The independence afforded by the latter may endow the individual's arguments with greater credibility, and certainly extensive referencing of one's own work can appear self-indulgent and even arrogant. It is a source of some disappointment to Foskett (1982) that, of the twenty-five references given in the bibliography of Urqhuart's book, twelve relate to the man himself and two associates. Yet, when a researcher has worked for a prolonged period at an advanced level in a highly specific area, there may be few others who are so well placed to comment on the phenomena involved.

Not only must the writer make decisions on the balance to be struck between the use of their own work and that of others, he or she must also consider the prominence to be given to schools of thought that conflict with their own. Clearly, some coverage is essential if the reader is to be given sufficient information to reach adequate conclusions about the truth of or justification for each of the author's statements. Where one of the intentions of the author is to challenge accepted wisdom, he or she may be keen to engage with opposing views so as to counter them with his or her own arguments. Whatever the intent of the writer, an 
honest approach to disclosing the appropriate information is paramount. In discussing criteria for ensuring quality in qualitative research, Lincoln indicates that "the extent to which alternative voices are heard" is a mark of the "openness" and "engagement" of any text $(1995,283)$, and this characteristic is equally a trademark of a sound 'principles' paper. A reader could well be wary of the claims of an author who draws only on source material that supports his or her position, feeling the piece to be obviously one-sided; although, as Shenton and Hay-Gibson (2009) acknowledge, writers may fear that to give too much attention to contrasting research findings or the ideas of others who take an opposing attitude is to weaken their own position.

Given that much of any 'principles' paper consists of individual discussions centred on separate assertions, there is an obvious danger of fragmentation. In order to forge at least a degree of unity, the author may choose to rank the statements according to importance or group them by topic. An instance of the latter approach can be seen in Table 3, which shows how Shenton (2007) arranged his ten paradoxes of young people's information behaviour in terms of six themes. Faibisoff and Ely (1976) take a similar approach. In stating their fourteen generalisations about information needs, they present them under four headings:

- the behaviour of the user;

- the nature, amount and source of information being sought;

- the quality of information;

- timeliness of the information.

The writer's efforts to facilitate categorisation by identifying links between the individual statements may also ultimately give rise to the creation of an integrated, higher level construct, such as a model.

Shenton's work differs from that of Faibisoff and Ely (1976) and is unusual overall in that, in his conclusion, he groups his statements again, here in terms of the types of anomaly which lead to the paradoxes.

\section{Writing a 'principles' paper}

Before closing this article with a few concluding observations, it seems appropriate to offer some advice for readers who are interested in writing their own 'principles' paper. The ten numbered points that follow are designed to take the reader through the key stages step by step.

1. Identify an overall area of interest and, if necessary, a more particular focus.

2. Determine who will form your intended readership. Broadly, are you targeting academics or practitioners?

3. Think about what use you envisage your readership will make of the principles and how they form part of your own wider programme of work (if you are undertaking one). 


\begin{tabular}{|l|l|}
\hline Themes/groups & Paradoxes \\
\hline $\begin{array}{l}\text { Connecting users with } \\
\text { information }\end{array}$ & $\begin{array}{l}\text { The effects of a library's procedures with regard to user } \\
\text { attitudes and behaviour are frequently inconsistent with } \\
\text { the organisation's aims. } \\
\text { In order to access information in a source, the user } \\
\text { must often apply knowledge that he or she does not yet } \\
\text { possess. }\end{array}$ \\
\hline Users' attitudes and strategies & $\begin{array}{l}\text { Young people are often highly critical of particular } \\
\text { information resources yet continue to use them } \\
\text { habitually. } \\
\text { Despite the sophistication of today's 'information age', } \\
\text { youngsters frequently follow a basic formula for action } \\
\text { when finding and using information. }\end{array}$ \\
\hline $\begin{array}{l}\text { Relevance of advocated } \\
\text { practices }\end{array}$ & $\begin{array}{l}\text { Verification of information in sources is widely } \\
\text { advocated, but strategies for implementing this process } \\
\text { may be of questionable real value. } \\
\text { Information skills models that take a linear, rather than } \\
\text { dynamic, perspective often imply that sources are } \\
\text { investigated once the need has been determined; but in } \\
\text { real life, knowledge of sources often itself triggers an } \\
\text { information need. }\end{array}$ \\
\hline $\begin{array}{l}\text { Priorities for the information } \\
\text { specialist }\end{array}$ & $\begin{array}{l}\text { Library patrons' reduced reliance on library staff } \\
\text { (resulting from effective programmes of user } \\
\text { education) may deprive staff of opportunities to learn } \\
\text { more about the information needs of their patrons. }\end{array}$ \\
\hline $\begin{array}{l}\text { Certain phrases used in the 'information world' that are } \\
\text { designed to explain are ambiguous and may cause } \\
\text { confusion rather than dispel it. } \\
\text { New expressions in library and information science } \\
\text { frequently juxtapose contrasting ideas or apply long- } \\
\text { accepted terms in unfamiliar contexts, thereby creating } \\
\text { confusion. } \\
\text { behaviour may misrepresent some of its aspects. }\end{array}$ \\
\hline
\end{tabular}

Table 3: Grouping method employed by Shenton (2007) on his ten paradoxes of young people's information behaviour. 
4. Decide on the inspiration for your principles. Will they emerge from your experience as an information professional, your own research, or the literature of others?

5. Using the chosen material, look to draft each principle as a short statement. It should be a one-sentence summary of the relevant knowledge or wisdom.

6. Discuss the issues surrounding each principle in a paragraph or two. Look to strike an appropriate balance in the material you use.

7. Assess carefully evidence that would seem to contradict your principles. Do any need to be revised?

8. Ascertain whether it is necessary (or possible) to test any of the principles further before finalising them. How universal do you intend them to be?

9. Explore how the principles can be linked or grouped.

10. Once you are satisfied with your principles and any accompanying text, give thought to how they can best be written up. Consider especially how the piece is to be structured.

\section{Conclusions}

Citing various publications from library and information science, the author has explored in this article the nature of the 'principles' paper. He has highlighted instances in which particular works have made a significant impact on the thinking of others and demonstrated the possibilities offered by an article of this kind. Although he has drawn heavily on material pertaining to information behaviour, readers whose interests lie in other areas of LIS will doubtless recognise the potential for such papers in their own fields.

'Principles' papers hold appeal to their readers as they can see at a glance the key matters raised; the main points are not lost within the whole text and no burden falls on the reader to extract them. They can also provide future researchers with inspiration for further projects as they may tempt new investigations into the pertinence of the statements in other environments and situations, whilst they can offer professionals a basis for good practice. Durrance makes no secret of the debt she owes to "generalized statements... taken from studies of information seeking on a wide variety of topics", acknowledging specifically that, in relation to her own study, they "set the tone for an analysis of the information-seeking behavior $[$ sic $]$ " of members within the group of interest to her $(1984,96)$.

The process of writing a paper of this type is itself frequently worthwhile. Academics appreciate the opportunity it provides in summarising evidence and creating abstract statements, and practitioners benefit from examining, from a more detached perspective, issues arising in their work and then constructing wider 'sense' by integrating their own insights with those of others. Whereas certain types of paper are expected to adhere to a rigorous and well-established form, that of the 'principles' paper is less prescribed, and this flexibility will be welcomed by authors who relish freedom in making their own decisions. Clearly, however, the type of issues raised, the style of writing adopted and the nature of 
the evidence used to support the claims must be commensurate with the targeted readership, whether this be practitioners or academics.

How individual principles are to be united is left to the writer to decide. The task of developing some overall cohesion by linking the assertions may facilitate the process of model-creation since, as Boshear and Albrecht (1977) note, a typical model will itself show interrelationships between the individual aspects of a system or event. Indeed, just as a model may lead to the development of a theory (Bates, 2005), a 'principles' paper may lead to the construction of a model.

However, it is unlikely that a 'principles' paper will purposely be written with this in mind.

Principles may also form raw material for the creation of models by later writers. Returning for a moment to Ranganathan's work, Noruzi (2004) recognises that "book", "reader" and "library" constitute the "basic elements" within his laws. As these components are clearly related, it is not inconceivable that a model uniting all three could be developed, especially if Ranganathan's ideas are used in concert with other material pertinent to the laws.

Authors must strike some difficult balances when writing a 'principles' paper, such as the prominence that should be given to their own material relative to that of others; or the prominence that should be given to evidence that supports their position relative to that which contradicts it. These are questions which are not easily answered but any author who reaches a successful resolution may well ultimately produce a paper that, in years to come, is not only cited, but is also influential.

\section{References}

Ahituv, N. and Neumann, S. (1990) Principles of information systems for management. $3^{\text {rd }}$ ed. Dubuque, IA: W.C. Brown.

Allen, B. L. (1996) Information tasks: toward a user-centered approach to information systems. San Diego, CA: Academic Press.

Bates, M. J. (2005) An introduction to metatheories, theories, and models. In:

Fisher, K. E., Erdelez, S. and McKechnie, L. (eds.) Theories of information behavior. Medford, NJ: Information Today. 1-24.

Beaulieu, M. (2003) Approaches to user-based studies in information seeking and retrieval: a Sheffield perspective, Journal of Information Science, 29(4), 239-248.

Bloom, B. S. (ed.) (1956) Taxonomy of educational objectives: the classification of educational goals. Handbook 1, cognitive domain. London: Longmans.

Boshear, W. C. and Albrecht, K. G. (1977) Understanding people: models and concepts. La Jolla, CA: University Associates.

Case, D. O. (2007) Looking for information: a survey of research on information seeking, needs, and behavior. $2^{\text {nd }}$ ed. London: Academic Press.

Chowdhury, G. G., Burton, P. F., McMenemy, D. and Poulter, A. (2008)

Librarianship: an introduction. London: Facet. 
Costa, A. L. and Kallick, B. (2009) Describing 16 Habits of Mind. URL: http://www.instituteforhabitsofmind.com/resources/pdf/16HOM.pdf [accessed 11.06.2012].

Dervin, B. (1976) Strategies for dealing with human information needs: information or communication? Journal of Broadcasting, 20(3), 324-333.

Dervin, B. (1983) An overview of sense-making research: concepts, methods, and results to date. International Communication Association Annual Meeting, Dallas, Texas, May 1983.

Dervin, B. (1997) Given a context by any other name: methodological tools for taming the unruly beast. In: Vakkari, P., Savolainen, R. and Dervin B. (eds.) Information seeking in context. London: Taylor Graham. 13-38.

Durrance, J. C. (1984) Armed for action: library response to citizen information needs. New York: Neal-Schuman.

Ellis, D. (1989) A behavioural approach to information retrieval system design, Journal of Documentation, 45(3), 171-212.

Elsevier (2007) Hints and tips on how to write for publication in academic and professional journals. URL:

http://www.writingforpublication.com/pageturning doc/how\%20to.pdf [accessed 09.11.2011].

Emerald (2011) How to... write an abstract. URL:

http://dev.emeraldinsight.com/authors/guides/write/abstracts.htm?part=1\&view $=\mathrm{p}$ rint\&PHPSESSID=06fcimv0nc16n9bjr6iq11er07 [accessed 11.06.2011].

Faibisoff, S. G. and Ely, D. P. (1976) Information and information needs, Information Reports and Bibliographies, 5(5), 2-16.

Foskett, D. J. (1982) Review: The Principles of Librarianship, Journal of Librarianship, 14(2), 137-139.

Gorman, M. (1998) Our singular strengths: meditations for librarians. Chicago: American Library Association.

Informed Librarian Online (2008) URL:

http://www.informedlibrarian.com/this_month.cfm [accessed 05.02.2008].

Journal of the American Society for Information Science and Technology (2011) Author guidelines. URL:

http://onlinelibrary.wiley.com/journal/10.1002/(ISSN)1532-

2890/homepage/ForAuthors.html [accessed 09.11.2011].

Lincoln, Y. S. (1995) Emerging criteria for quality in qualitative and interpretive research, Qualitative Inquiry, 1(3), 275-289.

Line, M. (1994) Obituary: Donald Urquhart. Independent, 13 December 1994.

URL: http://www.independent.co.uk/news/people/obituary-donald-urquhart1387364.html [accessed 09.11.2011].

Maykut, P. and Morehouse, R. (1994) Beginning qualitative research: a philosophic and practical guide. London: Falmer. 
Noruzi, A. (2004) Application of Ranganathan's laws to the Web, Webology, 1(2) [online]. URL: http://www.webology.org/2004/v1n2/a8.html [accessed 11.06.2012].

Ranganathan, S. R. (1931) The five laws of library science. Madras: Madras Library Association.

Salmon, P. (1992) Achieving a PhD: ten students' experience. Stoke on Trent: Trentham Books.

Shenton, A. K. (2007) The paradoxical world of young people's information behavior, School Libraries Worldwide, 13(2) [online]. URL: http://www.iaslonline.org/pubs/slw/july07-shenton.htm [accessed 11.06.2012].

Shenton, A. K. (2009) Information literacy and scholarly investigation: a British perspective, IFLA Journal, 35(3), 226-231.

Shenton, A. K. (2010) Paradoxes of young people's information behaviour revisited: insights from a practitioner, School Libraries in View, 30 [online]. URL: http://www.cilip.org.uk/get-involved/special-interestgroups/school/publications/journal/Documents/Shenton\%20_Gorman_E.pdf [accessed 11.06.2012].

Shenton, A. K. and Hay-Gibson, N. V. (2009) Dilemmas and further debates in qualitative method, Education for Information, 27(1), 21-37.

Shenton, A. K. and Johnson, D. M. (2010) The modern school library: caveats, anomalies and dilemmas for the information professional, School Librarian, 58(1), 11-13.

Staniów, B. (2008) Nauczyciel bibliotekarz wobec paradoksów zachowań informacyjnych uczniów, Poradnik Bibliotekarza, 5, 3-5.

Urquhart, D. (1981) The principles of librarianship. Leeds: Wood Garth.

Urquhart, D. (1990) Mr. Boston Spa. Leeds: Wood Garth.

Williams, P. and Rowlands, I. (2007) Information behaviour of the researcher of the future: the literature on young people and their information behaviour $-a$ British Library/JISC study. URL: http://www.jisc.ac.uk/media/documents/programmes/reppres/ggworkpackageii.pd $\underline{\mathrm{f}}$ [accessed 11.06.2012]. 
Open access and copyright

Library and Information Research is an open access journal. A freely available copy of this paper may be downloaded from the journal's website:

http://www.lirgjournal.org.uk/lir/ojs/index.php/lir.

Copyright and associated moral rights in works published in Library and Information Research are retained by the author(s) but this paper may be used freely, with proper attribution, in educational and other non-commercial settings. 